\title{
Embates na sociedade fluminense: a experiência do Prado Guarany (1884-1890)
}

\author{
Conflicts in the Fluminense Society: \\ The Experience of Prado Guarany (1884-1890)
}

\author{
Victor Andrade Melo* \\ André Leonardo Chevitarese ${ }^{\star *}$
}

\section{Resumo}

O objetivo deste estudo é discutir a experiência do Prado Guarany, um dos hipódromos que houve no Rio de Janeiro do século XIX, ativo entre os anos de 1884 e 1890. Ao interpretar seu modus operandi e os posicionamentos sobre seu funcionamento, esperamos lançar um olhar sobre certos embates ocorridos entre distintos grupos da sociedade fluminense, suas motivações e repercussões na construção de memórias da cidade. Para alcance do objetivo, ainda que também tenhamos utilizado documentação governamental, prioritariamente fizemos uso de revistas e jornais publicados no período em tela.

Palavras-chave: história do Rio de Janeiro; história do esporte; turfe.

\section{Abstract}

The objective of this study is to discuss the experience of the Prado Guarany, one of the racecourses of Rio de Janeiro in the 19th century, active between the years 1884 and 1890. In interpreting its modus operandi and the points of view on its functioning, we hope to reflect about certain conflicts that occurred between different groups of the Rio de Janeiro society, their motivations and repercussions in the construction of the city memories. In order to reach the goal, even though we have also used governmental documentation, we primarily made use of magazines and newspapers published in the period. Keywords: Rio de Janeiro History; sport History; horseracing.

\footnotetext{
* Universidade Federal do Rio de Janeiro (UFRJ), Programa de Pós-Graduação em História Comparada. Rio de Janeiro, RJ, Brasil. victor.a.melo@uol.com.br <https://orcid.org/0000-0002-1983-1475>

** Universidade Federal do Rio de Janeiro (UFRJ), Programa de Pós-Graduação em História Comparada. Rio de Janeiro, RJ, Brasil. andrechevitarese@yahoo.com.br <https://orcid.org/0000-0003-0041-0889>
} 
Nos dias de hoje, no Rio de Janeiro há somente uma agremiação ativa de turfe, o Jockey Club Brasileiro, fundado em 1932 pela união do Jockey Club - criado em 1868 - com o Derby Club - inaugurado em 1885. Ainda que siga atraindo muitos adeptos, reunidos atualmente menos nas arquibancadas de seu belo hipódromo (localizado no bairro da Gávea) e mais nas muitas casas de apostas espalhadas pela cidade (Labronici, 2016), as corridas de cavalos não chamam mais a atenção como antes.

No século XIX, o quadro era bastante distinto. Parte significativa da população, gente de diversos estratos sociais, acompanhava com grande atenção os eventos turfísticos. Nos anos 1880, as corridas de cavalos se tornaram uma das mais apreciadas opções de entretenimento do Rio de Janeiro (Melo, 2001). Muitos foram os clubes que promoveram páreos em hipódromos localizados em diferentes bairros da cidade, sem falar nos que existiam nos municípios vizinhos - Niterói, Nova Friburgo e Petrópolis.

Entre tais hipódromos, cinco se destacaram pela repercussão na imprensa e perfil dos associados, gente ligada a diferentes setores da elite fluminense: os mais famosos e longevos Prado Fluminense (do Jockey Club) e Prado Itamaraty (do Derby Club); os de vida mais breve, ainda que também celebrados, do Turf Club, do Hipódromo Nacional e o Prado Vila Isabel (que acolheu o Club de Corridas Vila Isabel e o Derby Fluminense).

Houve, todavia, outro hipódromo que se destacou pelo oposto, pelo conjunto de olhares negativos que recebeu: aquele que se localizava numa pequena região da cidade espremida entre o Santo Cristo e São Cristóvão, denominada Vila Guarany/Praia Formosa. O Prado Guarany durou apenas 6 anos (18841890), mas deixou marcas controvertidas.

Um dos que consagrou, a posteriori, sua má fama, relacionada às supostamente deficientes instalações e à ocorrência constante de tribofes, ${ }^{1}$ foi o memorialista Luiz Edmundo: "Qual velho não se lembrará, hoje, do famoso prado que se chamou Vila Guarany, cognominado Maxixe, ${ }^{2}$ que existiu para as bandas da Praia Formosa e do qual se pode dizer que, sendo o mais tribofeiro entre todos os de seu tempo, foi, ainda, o que mais sofreu a ação violenta e justa da massa popular, que vivia constantemente a depredá-lo?” (Edmundo, 1957, p.849).

Outro memorialista que consagrou a ideia de baixa qualidade das instalações e de desorganização dos eventos dos clubes que promoviam corridas no Prado Guarany foi Cássio Costa. Para ele, "as arquibancadas eram de madeira e sem cobertura e os animais que tomavam parte em sua carreira, em sua 
maioria, eram peludos ou já afastados das pistas do Jockey Club e do Prado Vila Isabel. Um pradozinho de $3^{\text {a }}$ ordem" (Costa, 1961, p.63).

É possível que esse hipódromo fosse mesmo mais modesto. Aliás, deixou poucos registros na malha urbana, ao contrário dos outros, identificados até mesmo nos mapas da cidade. É provável que por lá houvesse mesmo muitos tribofes. Mas esses conflitos também existiam em grande quantidade em outros prados. Por que então só o Prado Guarany foi alcunhado de "Maxixe"? Por que tantos posicionamentos negativos a seu respeito foram forjados? Tais ocorrências ajudariam a entender algo da dinâmica citadina?

O objetivo deste estudo, tendo em vista tais questões, é discutir a experiência do Prado Guarany. Ao interpretar o seu modus operandi e os posicionamentos sobre seu funcionamento, esperamos lançar um olhar sobre certos embates que houve entre distintos grupos da sociedade fluminense (especificamente entre elites ligadas à aristocracia e burguesia urbana e estratos médios), suas motivações e repercussões na construção de memórias da cidade, especificamente prospectadas nos posicionamentos de periodistas. ${ }^{3}$

Para alcance do objetivo, ainda que também tenhamos utilizado documentação governamental, prioritariamente fizemos uso de revistas e jornais publicados na cidade no período de funcionamento do Prado. Consideramos que a imprensa já desempenhava papel de fórum público, com os cronistas não só divulgando as atividades cotidianas, como também se posicionando frente às novidades que se organizavam na cena urbana. A propósito, entre os assuntos frequentemente abordados se encontravam os eventos relacionados ao turfe.

Para trato do material coletado, consideramos os posicionamentos dos cronistas como pontos de vista sobre o ocorrido, não a expressão da verdade. Optamos por apresentar o perfil do periódico apenas quando o consideramos, de fato, condicionador da análise/interpretação. Deve-se ter em conta que parte das informações utilizadas foram obtidas em anúncios das corridas - publicados em diversos jornais - ou descrições bastante sucintas dos eventos turfísticos.

Obviamente, sabemos do limite do uso de periódicos no que tange ao alcance de nosso objetivo. Em outras fases do projeto, temos como objetivo ampliar esse escopo de consulta. Ainda assim, cremos que, mesmo com as restrições assumidas, o trato do material foi suficiente para nos permitir lançar um olhar sobre o tema. 


\section{Do Boat Rink ao Prado Guarany}

A Vila Guarany foi um pequeno bairro que surgiu, na virada dos anos 1870 para a década seguinte, com o aterro da Praia Formosa. Em boa parte, sua ocupação foi impulsionada pelas atividades da Empresa Ferro-Carril Vila Guarani (Cardoso, 1987), de propriedade de Francisco Eugênio de Azevedo. No mapa (Figura 1), pode-se ter uma noção do espaço.

Figura 1 - Planta da Cidade do Rio de Janeiro e dos Subúrbios, 190?, por Ulrik Greiner.

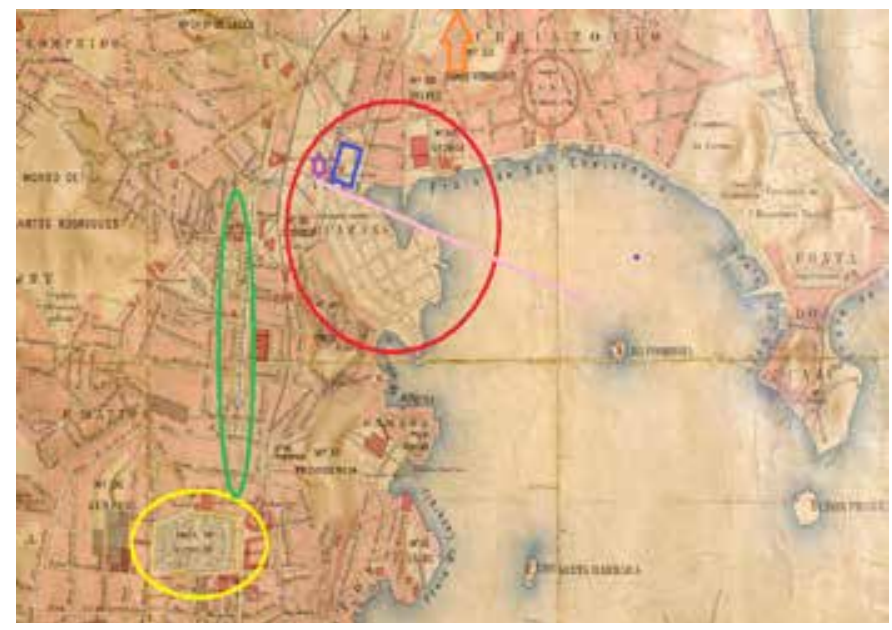

O círculo vermelho marca a antiga Vila Guarany. O retângulo azul, o local do Prado Guarany. A estrela lilás identifica a atual Estação Leopoldina (erguida em 1926). Perceba-se que se trata de região próxima ao Campo de São Cristóvão (em marrom) e da Quinta da Boa Vista (indicada na seta laranja). O círculo amarelo marca o Campo de Santana, a elipse verde sinaliza onde viria a ser a atual avenida Presidente Vargas. A reta rosa marca o que seria a atual Avenida Francisco Bicalho.

Conforme a cidade se espraiava - processo que teve início já na segunda metade do século XVIII e se intensificou nas décadas finais do XIX - e via diversificar suas vocações socioeconômicas, distintos grupos se consolidavam. Crescia o poder e a influência de uma burguesia urbana, formada por empreendedores que dirigiam as novas opções de negócio, especialmente as 
pioneiras iniciativas fabris e os serviços de reforma urbana. Sua principal interlocutora, também integrando as elites, era a antiga aristocracia, donos de terras geralmente envolvidos com o comércio agropecuário. ${ }^{4}$

Também se consolidava um ativo (muito embora reduzido) estrato médio, integrado por gente de formação secundária que ocupava postos de direção no mercado de trabalho ou profissionais liberais de ensino superior que viviam de sua profissão, bem como donos de pequenos negócios e militares oficiais de patente intermediária (Popinigis, 2007).

Da mesma forma, uma classe trabalhadora começava a se forjar e mais claramente reivindicar melhores condições de vida. Integravam ainda a sociedade fluminense os de poder aquisitivo mais baixo, trabalhadores livres, escravos libertos e escravos de ganho, entre outros.

Deve-se ter em conta que diversos conflitos marcavam a relação entre os distintos estratos sociais. Uma parte deles relacionava-se aos interesses de classe e possibilidades de acesso ao poder. Isso se manifestava inclusive no que tange à possibilidade de frequentar certos lugares e à exibição de símbolos de status e distinção. Outros tinham a ver com projetos de nação ou compreensões sobre o futuro do país, destacando-se os confrontos entre escravistas e abolicionistas e entre monarquistas e republicanos. Havia ainda os embates ligados às questões cotidianas, entre as quais os possíveis usos da cidade.

Naquele cenário, uma das formas mais usuais de organização entabuladas foi a criação de clubes de diversas naturezas, inclusive os esportivos (Fonseca, 2008). Essas agremiações dramatizavam o crescimento da importância do âmbito do entretenimento na dinâmica citadina. Ao seu redor, forjavam-se estratégias de autoidentificação, de auxílio mútuo, de fortalecimento de alianças com interesses diversos. Como sugerem Victor Melo e Fabio Peres:

Essas agremiações eram uma expressão da ampliação de espaços sociais nos quais antigas e novas elites (compostas por profissionais liberais, industriais, homens de negócios, ilustrados da política e da administração pública etc.), bem como grupos mais populares, procuravam construir laços, intra e extraclasses, em tese mais abertos e igualitários. Serviam bem ao propósito de demonstrar o alto grau civilizacional dos envolvidos. (Melo; Peres, 2014, p.35)

Quando surgiu a Vila Guarany, estava bem desenvolvido no Rio de Janeiro um mercado de diversão que se espraiava pari passu com o processo de urbanização (Melo, 2017). Não surpreende que logo surgissem 
entretenimentos no novo bairro que procurava se sintonizar com o conjunto de mudanças da cidade, com os ares de modernidade que vinham do exterior e se dramatizavam em algumas dimensões materializadas na região: o progresso ocasionando a conquista de novas zonas e ampliando a mobilidade urbana. Entre os divertimentos, destacavam-se os circos e, notadamente, as festas religiosas, que já passavam por alterações de dinâmica, assumindo um formato que lembrava outros entretenimentos que se organizavam. ${ }^{5}$

O Prado Guarany era mais um dos divertimentos que se estruturaram no novo bairro. A princípio, porém, o que se instalou foi outro estabelecimento. Em 1880, Saul Severino da Silva ${ }^{6}$ recebeu "autorização para organizar uma companhia destinada a corridas de botes por água ou em planos com o título de Boat Rink". ${ }^{7}$

Somente em 1884 Silva conseguiu concretizar a ideia do Boat Rink. Provavelmente foi escolhida a Vila Guarany/Praia Formosa pela grande oferta de terrenos, pela melhoria do transporte público ${ }^{8}$ e pelo crescimento populacional da área. ${ }^{9}$ Em 7 de setembro daquele ano, oferecendo provas de duas modalidades que se tornaram valorizadas na cidade - o remo e as corridas a pé (Melo, 2001; Melo; Peres, 2016) -, inaugurou-se o estabelecimento. O preço da entrada era acessível, isso é, tinha valor similar a outros entretenimentos da cidade. ${ }^{10}$ Havia venda de poules que, no decorrer do tempo, foram ficando mais baratas (Costa, 1961). As apostas ajudavam a atrair o público e viabilizar financeiramente o empreendimento.

$\mathrm{O}$ formato da iniciativa era sensivelmente diferente dos clubes esportivos, aproximando-se mais dos rinques de patinação. Isso é, não era uma iniciativa de associados sem fins lucrativos. O proprietário dependia da arrecadação das entradas, das vendas de poules e do apoio de empresas (na aquisição dos prêmios) para garantir os lucros.

O Boat Rink logo se integrou à dinâmica local. Transformou-se, por exemplo, num dos locais das festas promovidas pela Empresa Ferro-Carril Vila Guarany. Uma das mais notáveis dessas ocasiões foi a comemoração do $1^{\circ}$ aniversário da companhia, festejo que contou com exibições de bandas de música, luz elétrica e fogos de artifício, bem como páreos de remo, corridas a pé e de velocípedes (Gazeta da Tarde, 22 nov. 1884, p.4). Segundo um cronista, "apesar da chuva que caiu à noite, o povo em ondas flanava por ali" (Gazeta da Tarde, 24 nov. 1884, p.2). ${ }^{11}$

O perfil dos dirigentes do evento nos dá uma ideia do grupo societário envolvido. Eram oficiais ainda jovens (como os capitães Francisco Xavier 
Baptista e Justiniano da Rocha, bem como o alferes João Ignacio Cardoso) e profissionais liberais, como o advogado Alfredo Pinto de Carvalho. Os inscritos nas provas tinham perfil semelhante. As propagandas por vezes ressaltavam a participação da "classe comercial", um grupo que, de fato, esteve muito envolvido com as atividades esportivas na segunda metade do século XIX (Melo; Peres, 2014). Não é improvável tratar-se de pessoas de estrato médio. Se não eram exatamente membros das elites, é possível que fossem pessoas que tinham uma vida com conforto superior ao da maioria da população fluminense.

Aparentemente, mesmo tendo em conta possíveis exageros de alguns cronistas, em muitas ocasiões o Boat Rink contou com a presença de bom público. Um entusiasmado periodista, ao comentar com detalhes um evento promovido no estabelecimento, chegou a afirmar que "sem que por ventura queiramos passar por exagerados, podemos garantir que ontem, se não toda, pelo menos uma grande parte da população desta cidade foi à grande festa" (Gazeta da Tarde, 2 dez. 1884, p.2). A Empresa Ferro-Carril eventualmente colocava mesmo bondes extras para facilitar a chegada dos frequentadores que desembarcavam na Estação da Praia Formosa, localizada nas redondezas.

O estabelecimento logrou algum reconhecimento público. Um cronista chegou a entusiasmadamente sugerir que "decididamente é em Vila Guarany que a gente se diverte" (Revista Ilustrada, ano 9, n.395, 1884). Mereceu também uma breve referência do irônico Arthur Azevedo em uma de suas "revistas", peças cômicas que comentavam os principais acontecimentos anuais. Em Cocota, de 1885, citou o dramaturgo ao comentar o crescente interesse pelo esporte que grassou na sociedade fluminense: "Prado aqui, Derby além, Rink acolá, Boat-Rink, Foot-Rink... Rinks dos diabos que os carreguem! Corridas de cavalos, corridas de sendeiros, corridas de aranhas, de velocípedes, de homens, de meninos... É um não acabar! Um sorvedouro" (Azevedo; Sampaio, 1885, p.94).

Ao comentar um evento do Boat Rink, sugeriu um cronista que "não houve uma só desordem" (Gazeta da Tarde, 2 dez. 1884, p.2). De fato, o estabelecimento chegou a ser celebrado como um lugar refinado da cidade. Comentou um periodista na coluna "Mundo Elegante" da Gazeta da Tarde: "É de esperar que lá encontremos as nossas gentis leitoras, não só para mais uma vez apreciar a bela Vila Guarany, como divertimento anunciado, que é atraente, ainda mais quando os dignos diretores melhoraram a arena, colocando arquibancadas para as senhoras, que oferecem presentemente toda a comodidade" (12 out. 1884, p.2). 
Há que se ter em conta que os mais constantes elogios vinham mesmo da Gazeta da Tarde, periódico dirigido por José do Patrocínio. Esse importante personagem da história fluminense e nacional viveu em São Cristóvão quando era aluno da Faculdade de Medicina. Nessa ocasião, começou a frequentar o Clube Republicano e iniciou-se na função de jornalista. Era frequentador das atividades sociais das agremiações locais, inclusive do Boat Rink e do Prado Guarany (com o qual se envolveu como dirigente) (Costa, 1961).

No mesmo mês de inauguração, um grupo que frequentava o Boat Rink anunciou que nas instalações seria criado o Prado de Corridas Vila Guarany. Provavelmente, Saul Severino, que seguiu envolvido com o novo empreendimento, vislumbrava aumentar seu lucro - o turfe atraía mais gente e movimentava maiores quantias - e dividir com uma sociedade ampliada os custos da administração do negócio.

Durante alguns meses ainda seguiram sendo realizadas corridas a pé e regatas no Boat Rink, enquanto se promoviam as adaptações para se instalar o hipódromo. É de grande complexidade a construção desse equipamento esportivo. Há muitas exigências no que tange à pista, à estrutura para receber e acomodar os cavalos, às casas de apostas. A iniciativa requeria alto investimento, e muitos desafios deveriam ser superados. Os de ordem material não seriam os únicos.

\section{ESTRUTURANDO UM HIPÓDROMO}

Em dezembro de 1884, o cronista de Gazeta da Tarde anunciou a mudança de nome e de perfil do estabelecimento: saiu de cena o Boat Rink, entrou o Prado Guarany. Nos seus comentários deixou transparecer certa incompreensão com tal decisão, já que o antigo gozava de boa reputação. De toda forma, manifestou esperanças de que os resultados fossem ainda melhores (6 dez. 1884, p.2), o mesmo que perspectivava o periodista de A Folha Nova. Para este, a nova fase deveria ser aprovada pois ampliaria ainda mais o sucesso da instituição "que nos parece talhada para um grande futuro" (9 dez. 1884, p.3). ${ }^{12}$

De outro lado, desde as primeiras corridas surgiram críticas que depois se exponenciariam. Um cronista, ao comentar a inauguração do novo prado, sugeriu que, a despeito da modéstia do estabelecimento, a população o acolheu bem, tendo, contudo, a confiança abalada em função de "irregularidades havidas no meio de julgar" (Diário do Brasil, 12 dez. 1884, p.2). ${ }^{13}$ 
O perfil de sócios e dirigentes da Associação Prado Guarany, responsável por organizar os eventos turfísticos, guardava semelhanças com o do antigo Boat Rink, destacando-se o nome do capitão Marcolino Rodrigues da Costa Junior, sócio e dirigente da agremiação, futuro professor de equitação da Escola Militar.

O presidente Fernando Francisco da Costa Ferraz era importante médico e foi personagem de destaque no turfe, fundador e presidente do Jockey Club na transição para o século XX. Abolicionista, integrava um grupo distinto no interior da modalidade, ainda majoritariamente dirigida por gente da aristocracia. Ficou conhecido pelas polêmicas que ocasionou ao, mesmo sendo ligado a agremiações turfísticas, constantemente criticar e combater as apostas (Melo, 2001).

O primeiro programa do novo hipódromo (Gazeta da Tarde, 15 dez. 1884, p.3) apresentou boa variedade de provas: corridas sem e com obstáculos (steeple chase); para jóqueis profissionais e amadores (gentlemen riders); com animais do Brasil ou estrangeiros; com cavalos de "sangue" ou "pungas". O intuito era atrair amplo espectro de proprietários para garantir a emoção tão buscada tendo em vista atrair bom público.

Lembremos que, na ocasião, a cidade somente contava com o Jockey Club e com o Prado de Vila Isabel. As regras da modalidade ainda estavam sendo definidas. O Prado Guarany procurou proibir que se alterasse o nome de cavalos que já haviam corrido em outros hipódromos, para participarem dos páreos. Era uma tentativa de impedir os tribofes que já assustavam as sociedades turfísticas (Melo, 2001). Além disso, adotou-se o mesmo regulamento de corridas do Jockey. A antiga e na altura já prestigiosa agremiação era o exemplo a ser seguido.

De início, foi grande a expectativa criada pelos jornais. Exultou um cronista: "Com certeza o Prado Vila Guarany, que está preparado com todas as comodidades para o público, regurgitará de espectadores para apreciarem estas corridas que prometem ser esplendidas" (Brazil, 14 dez. 1884, p.2). Num momento em que as atividades do Jockey Club se interromperam - era usual que isso ocorresse no verão -, os adeptos do turfe comemoravam a possibilidade de seguir se divertindo.

Foi boa a repercussão da atividade inaugural do Prado Guarany, realizada em 14 de dezembro de 1884. Registrando a grande presença de público, ainda que também algumas deficiências na infraestrutura, os cronistas da Gazeta de 
Notícias, da Folha Nova, da Gazeta da Tarde e de Brazil elogiaram as corridas, perspectivando uma trajetória de sucesso para o novo hipódromo.

Esses bons resultados incentivaram a diretoria a promover de imediato novas corridas, dessa vez com um programa mais ambicioso de 11 páreos, que contou mesmo com maior número de animais inscritos. Percebe-se que poucas foram as provas de amadores, adotando-se um modelo mais tradicional.

O resultado de público parece ter feito jus ao investimento na organização e grande divulgação do evento. O movimento de apostas é expressão desse sucesso: angariaram-se 27:555\$00. Por se tratar de empreendimento mais modesto, pode-se considerar uma boa arrecadação, mesmo que abaixo do usual em outras agremiações. ${ }^{14}$ Há que se ter em conta que, por ser, como aponta Costa (1961), um hipódromo menor, havia limites físicos para receber mais frequentadores.

Com o sucesso das primeiras corridas, em março de 1885 a diretoria resolveu promover um tipo de atividade então muito comum no âmbito do entretenimento, um evento beneficente, com renda revertida para uma instituição de caridade, o Asilo da Mendicidade (Gazeta da Tarde, 18 fev. 1885, p.2). Essa era uma estratégia utilizada para forjar uma boa imagem do estabelecimento e ampliar o interesse do público (Melo; Peres, 2014).

As atividades do Prado Guarany pareciam, de fato, integradas à cidade. Se o hipódromo não recebia dos periódicos tanta atenção quanto os outros, tampouco havia notícias negativas. Em geral, a seu respeito se observou a boa presença de público e a adequada organização dos eventos.

Na realidade, parece ter funcionado melhor nos meses de verão. Quando o Jockey Club voltou a promover corridas, em maio de 1885, começou-se a sentir dificuldades na manutenção dos eventos do Prado Guarany. Além disso, logo começaria a funcionar o Derby Club (Melo, 2001), dividindo ainda mais o interesse dos espectadores.

A Gazeta da Tarde ainda seguiu exaltando o hipódromo da Vila Guarany, mas já com menos fervor. Os outros jornais rapidamente desviaram sua atenção para cobrir e constantemente elogiar a mais antiga sociedade turfística. Sobre o Jockey Club, não se economizaram reverências:

A associação não se poupa a despesas para melhorar não só seus divertimentos como para animar os criadores que concorrem às corridas com bons e bem tratados animais. Estamos certos que serão seus esforços coroados e no corrente ano terá espaço pequeno em suas arquibancadas para conter o público que procurar o 
Prado Fluminense como o lugar onde se diverte mais agradavelmente e onde se é tratado com a máxima amabilidade. (Gazeta da Tarde, 9 maio 1885, p.1)

O novo cenário passou a se refletir na queda de público e da movimentação de apostas, o que interferia no funcionamento do hipódromo por reduzir a capacidade de oferta de bons prêmios. Com isso, diminuía a possibilidade de atrair a inscrição de animais de melhor qualidade. Um cronista observou, por ocasião de certas corridas, que os cavalos "doentes e maltratados deram a maior decepção aos apostadores” (Gazeta da Tarde, 15 maio 1885, p.1). Com páreos menos emocionantes, diminuía o interesse dos adeptos pelo Prado Guarany.

O problema se acentuou quando começaram a surgir suspeitas de combinações de resultados nas corridas do Prado Guarany. Um leitor que assinou como Corisco publicou breve nota denunciando que "foi por terra a patota organizada" no hipódromo (Gazeta da Tarde, 4 maio 1885, p.3). O autor anônimo acompanhava com atenção as atividades, sempre pronto a denunciar possíveis falcatruas.

De toda forma, em algumas ocasiões houve bom público no Prado Guarany, bem como na imprensa elogios a "tão simpática” agremiação, "a qual tem oferecido tão bons divertimentos" (Gazeta da Tarde, 29 maio 1885, p.2). A diretoria da Associação Prado Guarany, todavia, por mais que tentasse, não conseguia fazer frente à fama e arrecadação do Jockey Club.

Em busca de maior prestígio e da garantia de viabilidade econômica para o empreendimento, a diretoria resolveu ceder suas instalações para outras atividades. Por exemplo, o Congresso Ginástico Português usou o hipódromo para promover provas de corridas a pé entre seus associados (Diário Portuguez, 9 maio 1885, p.3). Essa também era uma estratégia para reforçar a boa imagem do Prado, tentativa de forjar a ideia de que estava sintonizado com os movimentos mais elegantes da cidade.

Outra estratégia adotada pelo Prado Guarany, com a melhoria do conforto das instalações - antiga questão que sempre cercou o hipódromo -, foi a tentativa de se instituir um Grande Prêmio anual, a exemplo do que ocorria na agremiação mais antiga. A ideia era que o "Independência do Brasil" fosse oferecido na primeira corrida de setembro para cavalos de até 3 anos que também se tivessem inscrito para "correr o prêmio Cruzeiro do Sul da sociedade Jockey Club". 
Uma vez mais nota-se a forte referência à mais prestigiosa agremiação turfística. O Prado Guarany, todavia, seguiria encontrando problemas para manter-se em funcionamento.

\section{Problemas e restrições ao Prado Guarany}

A ocorrência de tribofes atrapalhou os intuitos da diretoria do Prado Guarany. Em corridas realizadas em junho de 1885, os conflitos foram intensos. Frente a um resultado suspeito, a diretoria cancelou uma prova, causando revolta nos espectadores que, enfurecidos, destruíram parte das arquibancadas e das grades da pista e a casa de poules. A confusão só acabou com a chegada da polícia, que determinou o fim do evento (Diário de Notícias, 26 jun. 1885, p.2).

A despeito do esforço da diretoria para organizar um programa mais equilibrado e emocionante, houve artimanhas de alguns jóqueis e proprietários que buscaram trapacear. O público, sentindo-se ludibriado, culpou a direção e reagiu com violência. Gazeta da Tarde, Gazeta de Notícias e O Paiz deram repercussão ao conflito.

A Associação entrou em crise depois desse acontecimento. Os prejuízos financeiros foram desanimadores. Após semanas sem atividades, o presidente interino, José Pereira de Barros, convidou os sócios para uma assembleia cujo intuito era decidir o futuro do Prado Guarany (Gazeta da Tarde, 8 ago. 1885, p.3). Assumiu a presidência Francisco de Assis Mascarenhas, membro de família tradicional que chegara ao Rio de Janeiro com a família real portuguesa, em 1808. O vice, Antônio Mariano de Azevedo Marques, e o secretário, Pedro Brant Paes Leme, eram também de famílias importantes. Costa Ferraz e José Pereira de Barros seguiram na direção, atuando no Conselho.

A primeira atividade dessa nova fase foi uma lembrança do passado da agremiação, provas de corridas a pé tendo como atração um célebre atleta que excursionava pelo Brasil, o italiano Bargossi. Outras duas apresentações semelhantes já tinham sido realizadas na cidade, ambas com grande sucesso. ${ }^{15}$ Vislumbrava a nova diretoria reposicionar o hipódromo no mundo elegante. Todavia, o resultado foi decepcionante: pouco público compareceu (O Paiz, 17 ago. 1885, p.2).

Percebe-se que seguiam na memória de alguns cronistas os acontecimentos anteriores. O periodista do Diário do Brasil foi contundente, lembrando "a serie brilhantíssima de revoltantes abusos que tanto escandalizaram a opinião 
pública" (1 out. 1885, p.2). Para ele, a reinauguração do Prado poderia até parecer bem organizada, mas nada fazia crer que o futuro seria diferente.

Em mais de uma ocasião, tornou esse cronista ${ }^{16}$ a atacar o Prado Guarany, especialmente a Costa Ferraz - para ele um dos principais responsáveis pelos problemas. Até mesmo o periodista do Jornal do Commercio mereceu reprimendas por criticar também as outras agremiações pelos tribofes e falcatruas. Segundo seu olhar, não havia comparação possível, "tribofeiro" era mesmo o Guarany. Para ele, o governo teria de agir e não deixar o hipódromo funcionar (Diário do Brasil, 8 out. 1885, p.1).

Considerando o já citado perfil desse periódico, pode-se sugerir que o cronista defendia os interesses dos aristocratas que se reuniam no Jockey Club (Melo, 2001). Mais ainda, sua implicância extrema com o Prado Guarany pode ter a ver com o perfil da diretoria, inclusive com a denotada participação de José do Patrocínio, que se opunha à manutenção da escravatura pela qual tanto se esmerou em defender o Diário do Brasil.

Cada vez mais se forjava a má fama do Prado sem que se apurasse se os problemas eram, de fato, responsabilidade do público, da diretoria, dos jóqueis, treinadores ou proprietários. Na hipótese de que a direção tivesse mesmo responsabilidade central nos conflitos, os olhares negativos para o Prado Guarany eram mais intensos do que aqueles que pendiam sobre outras agremiações, especialmente sobre o sempre exaltado Jockey Club.

A diretoria da Associação Prado Guarany ainda tentou usar de alguma influência política para manter ativo o hipódromo. Meses depois do último evento, divulgaram-se para 2 de dezembro as corridas de reinauguração, promovidas com apoio da Câmara Municipal para homenagear o aniversário do imperador Pedro II. Todavia, não houve bom número de animais inscritos, o que levou ao cancelamento dos páreos, algo celebrado pelo cáustico cronista do Diário do Brazil (14 out. 1885, p.2): "não concorrendo a inscrição, dando assim a maior prova da justiça que estigmatizamos esse prado de interesses inconfessáveis. Ainda Bem!”.

Provavelmente em razão do fracasso em organizar novas corridas, dos ataques públicos sofridos e dos problemas financeiros, em novembro de 1885 fundou-se uma nova associação no Prado Guarany, o Hipódromo Fluminense (pelo informado, sugerimos que incorporou o patrimônio da antiga agremiação). Assumiu a presidência Demerval da Fonseca, companheiro de José do Patrocínio na imprensa, com o qual lançou o quinzenário Os Ferrões, no qual 
criticavam a alta sociedade fluminense. Foi também seu parceiro no Cidade do Rio de Janeiro e na Gazeta de Notícias.

Como vice, assumiu José Rodrigues de Azevedo Pinheiro, engenheiro, professor de matemática e educador em muitos colégios do Rio de Janeiro. Entre os diretores havia antigos militares envolvidos com as corridas do Prado, como Paulo Pfaltzgrapff e Marcolino Rodrigues da Costa Junior.

A direção do novo clube promoveu mudanças no hipódromo, a começar pela raia, a fim de torná-la mais segura. Alterou-se a entrada e a fachada para facilitar a chegada dos frequentadores. Além disso, "as arquibancadas e a casa das apostas, o encilhamento e mais dependências foram completamente transformados e melhorados" (Vanguarda, 29 nov. 1885, p.1). O primeiro programa, todavia, não parecia muito ambicioso, com páreos para animais nacionais e "peludos".

A despeito dos problemas e limitações, a primeira repercussão não parece ter sido de todo negativa. O Diário de Notícias reconheceu avanços na "manutenção da ordem e disciplina", o que supostamente tornara o Prado Guarany capaz de "inspirar confiança aos sportmen e ao público" (8 dez. 1885, p.1).

Os cronistas de A Vanguarda e do Diário de Notícias foram bem generosos nos comentários. Para o primeiro, a atividade inaugural tratou-se de uma ocasião brilhante, justificando a presença de mais de 2 mil pessoas (10 dez. 1885, p.1). Para o segundo, sobre corridas realizadas no fim de dezembro, tratou-se de ocasião "extraordinária e animada, correndo a festa com muita ordem" (28 dez. 1885, p.1). Registrou-se claramente que não houvera trapaças, o ponto fraco da imagem do hipódromo. É importante destacar tais considerações para que se veja uma vez mais que nem só de referências negativas viveu o Prado Guarany.

A velha fama do hipódromo, todavia, volta e meia tornava a aparecer. $\mathrm{O}$ cronista do Carbonário, ao criticar a especulação e a ganância que grassava na sociedade fluminense, inclusive a que se manifestava nas corridas de cavalos, lembrou que o Jockey Club fora responsável por instituir as poules (29 jan. 1886, p.1). ${ }^{17}$ Boa parte da crônica, todavia, foi destinada a censurar o Prado Guarany, sugerindo que a diretoria estava diretamente imbricada nas trapaças identificadas.

Para esse cronista, tratava-se não de um espaço de estímulo ao desenvolvimento da raça de cavalos - um antigo argumento usado pelos que defendiam o valor das corridas de cavalos (Melo, 2001) -, mas sim de uma "fonte de 
renda" unicamente destinada a atender os interesses pessoais de seus dirigentes. Assim sendo, a nova agremiação nada mais seria do que um disfarce.

O cronista de A Semana foi ainda mais explícito, embora apontando para outra direção. Para ele, o turfe havia dado contribuições claras ao aperfeiçoamento da raça brasileira de cavalos. Isso somente teria sido possível por causa das poules, que garantiam a viabilidade financeira das agremiações. O problema teria sido o Prado Guarany, cuja diretoria se mostrava enfraquecida graças à ação controversa de Costa Ferraz que, embora não reprimisse os escândalos em seu hipódromo, na Câmara tentou proibir a realização de apostas na cidade (A Semana, 13 mar. 1886, p.82).

Tais acusações também cercaram a gestão de Costa Ferraz como presidente do Jockey Club, num momento em que essa agremiação passou por intensa crise (Melo, 2001). Sua forma polêmica de atuação ajuda a entender as críticas da imprensa. Para os que desprezavam as apostas, o Prado Guarany era o que de pior havia. Mesmo que sua arrecadação fosse menor, era considerado como local que somente se sustentava por facilitar a compra de poules, atraindo muitos interessados. Para os que as elogiavam, o hipódromo também era criticado tanto pelo perfil de um de seus principais dirigentes ${ }^{18}$ quanto pelos escândalos.

\section{O FIM DE UMA EXPERIÊNCIA}

Os motivos exatos não sabemos precisar. Provavelmente, uma vez mais os problemas financeiros foram determinantes. O fato é que durante 6 meses sumiram dos jornais as notícias sobre o Prado Guarany. As atividades se interromperam. Elas só voltariam a aparecer em agosto de 1886, já organizadas por uma nova agremiação: o Sport Fluminense. Como presidente, assumiu um personagem de relativa importância, o militar José de Almeida Barreto (O Paiz, 17 ago. 1886, p.2), que se tornaria figura proeminente por ser um dos primeiros a aderir à República ao lado de Deodoro da Fonseca, depois perseguido por Floriano Peixoto por ter sido um dos artífices e signatários do Manifesto dos 13 generais.

A nova agremiação era similar às anteriores. O grupo envolvido com a organização guardava muitas semelhanças, profissionais liberais e oficiais de patente intermediária (especialmente tenentes e capitães), alguns nomes já conhecidos mantendo-se na direção. Como de costume, anunciou-se que 
mudanças seriam promovidas nas instalações a fim de aumentar o conforto dos frequentadores e competidores.

O cronista que assinava como Max, em A Vida Moderna, "saudou" a reinauguração bem no espírito dos antigos críticos: "Haja festa e regalório! Vai ressuscitar o Maxixe. Aquele Maxixe da Praia Formosa que tem diversos nomes desde a criação do mundo até os nossos dias" (4 set. 1886, p.8). O pessimismo - ou preconceito - era explícito: "Surge agora o Sport Fluminense ... Que será? Vamô a Vê como diz Lourenço Alcoba, mas não é muita a nossa fé. Quem nasceu para maxixe não chega a pepino”. A nova iniciativa já nascia sob o signo da dúvida.

De toda forma, como nas outras ocasiões, alguns cronistas elogiaram a iniciativa. O cronista do Diário de Notícias exaltou o esforço de se fundar "uma sociedade séria, com bases sólidas e digna de atenção e proteção do público" (5 set. 1885, p.1).

O programa inaugural foi modesto (poucos páreos e cavalos de qualidade duvidosa), mas houve boa inscrição de animais. A Companhia de Carris Urbanos ofereceu carros extras partindo de diversos pontos da cidade, enquanto a Companhia Vila Guarany fez o mesmo para vários pontos de São Cristóvão (Diário de Notícias, 7 set. 1886, p.4).

O pouco anunciado nos jornais dá a impressão de que as corridas ficaram abaixo do que esperava a direção. Na realidade, a essa altura as atividades no Prado Guarany dependiam das decisões das outras agremiações turfísticas. Não podendo competir com elas, mudavam-se os dias e horários dos páreos de forma a conseguir atrair o público. Alguns eventos começavam mais cedo a fim de que os adeptos que assim desejassem pudessem posteriormente ir a algum outro hipódromo.

Costa (1961) lembra ainda que as agremiações do Prado Guarany passaram a reter menor porcentagem das apostas para aumentar os prêmios. Essa decisão dificultou ainda mais a viabilidade financeira do empreendimento. A conta não fechava, mas poucas saídas havia para se estabelecer em um campo que se tornara progressivamente competitivo.

O sempre crítico Max, de A Vida Moderna, comentou tais estratégias, entre as quais a de promover páreos nas quintas-feiras à tarde. Surpreendentemente, elogiou a iniciativa, percebendo que muitos adeptos estavam comparecendo ao Prado Guarany (2 out. 1886, p.7). De fato, as atividades passaram aparentemente a receber mais público, como ironizou certa feita o cronista de Gazeta da Tarde: "foram ao Sport Fluminense mais cidadãos do 
que os que concorreram ao escrutínio eleitoral no Município Neutro" (8 out. 1886, p.2).

O problema é que logo retornaram os problemas com páreos não realizados por não haver inscritos ou por intervenções de jóqueis trapaceiros, bem como confusões no julgamento das provas e na realização e pagamento das apostas. A velha mácula voltava a assombrar o hipódromo. O cronista de $O$ Paiz foi direto ao ponto: "O antigo Prado Guarany, vulgo Maxixe, já foi vítima de um desacato que o deixou com médico à cabeceira; urge, portanto, que a distinta diretoria do Sport Fluminense faça esquecer essas tristes tradições" (8 out. 1886, p.2).

Na transição para 1887, uma decisão atingiu em cheio o Sport Fluminense. A chefia de polícia, sem grandes esclarecimentos, proibiu a realização de corridas entre os meses de dezembro e abril, algo que se constituiu como uma tradição que percorreria toda a trajetória do turfe fluminense a partir de então. Curiosamente, o tradicional Jockey Club já adotava tal procedimento, agora estendido a todas as outras agremiações como obrigação.

Santos (2015) sugere que esse conjunto de ações restritivas ao funcionamento da modalidade, liderada pela sociedade turfística mais antiga, tratou-se de um processo de monopolização que tinha em conta garantir o acúmulo dos lucros advindos da prática. Alguns clubes resistiram mais tempo, como o Derby Club, que só encerrou suas atividades em 1932, quando se fundiu com o Jockey Club. Outros não conseguiram fazer frente e acabaram por fechar as portas.

Nos primeiros meses de 1887, os conflitos com os poderes constituídos deixaram registros. Frente a uma tentativa de promover corridas sem a devida licença e antes do período estabelecido pela norma, um fiscal da Câmara compareceu ao Prado Guarany para impedir a realização do evento. Ao ser notificado, Marcolino Rodrigues da Silva se negou a cumprir a ordem, sendo por tal postura acionada a delegacia local. ${ }^{19}$

Além disso, em maio de 1887, José do Patrocínio apresentou à Câmara um projeto de regulamentação da realização de corridas de cavalos, atingindo inclusive as apostas, algo que desagradou a todos do campo do turfe e da imprensa. ${ }^{20}$ Como Patrocínio era ligado ao Prado Guarany, as críticas acabaram resvalando no hipódromo. Como ocorrera no caso de Ferraz, considerou-se que era incoerente alguém ligado ao Maxixe apresentar esse tipo de proposta. 
Curiosamente, no mesmo mês, anunciou-se uma nova agremiação no Prado Guarany: o Sport Club. Assumiu a presidência Joaquim Duarte do Nascimento, oficial do Exército que atuava como administrador da Santa Casa de Misericórdia. O grupo societário envolvido se manteve similar aos das experiências anteriores, gente de estrato médio. Vale destacar que, de forma mais explícita, assumiu a diretoria sua tendência abolicionista, engajando o clube em ações de combate à escravidão (Costa, 1961).

Dessa vez, com maior rigor as sociedades turfísticas tomaram ações no sentido de coibir o funcionamento do Prado Guarany. O problema central foi a punição de jóqueis. Quando uma agremiação tomava tal decisão, o condutor tentava correr em outra. Assim sendo, os clubes decidiram em conjunto não permitir mais essa prática. A pena deveria valer para todos os hipódromos.

Todavia, o Sport Club - que não foi, de fato, convidado para a reunião em que se tomou tal decisão - não a acatava, até porque tinha dificuldade em compor o seu programa. Com isso, tornaram-se explícitas as restrições. Depois de grande debate, por sugestão de Paulo de Frontin ficou decidido que seria proibido de correr nas agremiações qualquer cavalo ou jóquei que tomasse parte em páreos promovidos no Prado Guarany. A ideia claramente anunciada era de que sua existência constituía um risco para o turfe fluminense.

Não foi a primeira vez em que isso ocorreu. Em 1886, o Diário de Notícias chegou a anunciar que havia "Um Prado em estado de sítio" (16 out. 1886, p.3). As outras agremiações tentaram, na ocasião sem sucesso, proibir cavalos e jóqueis de participar dos páreos no Guarany.

Mesmo com instalações mais modestas e programas que contavam com animais de menor qualidade, causava algum incômodo o Prado Guarany. Vejamos que no mesmo dia do glorioso Grande Prêmio do Jockey Club, ocasião que envolvia os mais importantes personagens da cidade e era anunciada efusivamente pelos jornais, o Sport Club conseguiu realizar suas corridas contando com bom público.

A arrecadação de apostas do Jockey foi de 251:300\$000, enquanto no Guarany beirou a metade desse valor. Parece pouco, mas não é mau, considerando a relevância do festejo da mais tradicional agremiação. As diferenças sempre foram grandes. Segundo o cronista de O Sport (10 dez. 1887, p.2), em 1886, o lucro das sociedades turfísticas com apostas foi: 


$$
\begin{aligned}
& \text { Derby Club - 6:778\$900 } \\
& \text { Jockey Club - 2:199 } \$ 400 \\
& \text { Vila Isabel - 2:378 } \$ 200 \\
& \text { Hipódromo Guanabara - 383\$700 } \\
& \text { Hipódromo Fluminense - } 118 \$ 900 \\
& \text { Sport Fluminense }-405 \$ 800
\end{aligned}
$$

De pronto se pode perceber que o mais tradicional Jockey Club perdia espaço para os mais novos Derby Club e Prado Vila Isabel. Os dois hipódromos menores - o de Niterói (Guanabara) e o Prado Guarany (Hipódromo Fluminense e Sport Fluminense) - dividiam ainda mais os lucros. Com esses dados, podemos entender melhor o já citado processo de monopolização sugerido por Santos (2015). A tentativa de estabelecer restrições tinha em conta também a questão dos lucros, ainda que se centrasse em argumentos relacionados a status e distinção.

Como nas experiências anteriores, o Sport Club buscou saídas para fugir ao controle e às restrições das outras agremiações, entre as quais estabelecer horários alternativos de corridas. Como naqueles casos, havia público regular. Por que sempre o Prado Guarany manteve alguma popularidade? Facilidade de deslocamento poderia ser uma das explicações. Mas provavelmente a maior motivação era o menor custo para jogar (Costa, 1961).

No fundo, boa parte dos adeptos tinha mais interesse no ato de apostar do que na performance esportiva em si, num momento em que os jogos de azar se tornaram muito valorizados na cidade (Melo, 2001). No Prado Guarany, os prêmios eram menores, mas as poules eram mais acessíveis, oportunizando os de poucos recursos a desfrutar algumas tardes de diversão (Costa, 1961).

Além disso, como vimos, não havia homogeneidade na cobertura da imprensa. Se alguns cronistas criticavam ou mesmo desprezavam o Prado Guarany, outros elogiavam suas atividades, considerando-o mesmo, ainda que mais modesto, elegante e adequado aos que buscavam um bom divertimento. A construção de memória posterior, que o registrou apenas como Maxixe, deixou de ter em conta que essa ideia não era única.

Há que se considerar, portanto, os conflitos entre diferentes estratos envolvidos com as agremiações como um fator determinante para estabelecer quais olhares preponderaram. O Prado Guarany era o único dirigido por membros de estrato médio, gente que tinha boa condição de vida, alguma influência política, 
mas não integrava stricto sensu a elite econômica da cidade. Aristocratas e burgueses se organizavam ao redor do Jockey Club e do Derby Club.

O Sport Club ainda se manteve em atividade nos anos de 1888 e 1889. Em 1890, planejou-se um evento de exibição, a ascensão de um balão conduzida por uma famosa aeronauta, Miss Alma. Frente à impossibilidade de realização, parte do grande público presente reagiu e tentou invadir o hipódromo, sendo contida pela ação policial (Gazeta da Tarde, 24 mar. 1890, p.1). Parece que o Prado não conseguia fugir dos tribofes que historicamente o marcaram.

O que impediu a realização do evento foi uma enchente resultante de intensas chuvas que causaram muita destruição na cidade, na região de São Cristóvão e na Vila Guarany, inclusive no Prado. Pouco depois anunciou-se a sua venda (Diário do Comércio, 5 maio 1890, p.2). Encerrava-se a trajetória do hipódromo da Praia Formosa.

\section{CONSIDERAÇÕES FINAIS}

Em junho de 1885, Cosme, o irônico cronista de O Mequetrefe (10 jun. 1885 , p.3), percebendo que o gosto pelas corridas de cavalos se difundira na sociedade fluminense, sendo especialmente apreciadas as apostas, fez uma contundente apreciação: “O Zé Povinho sabe tudo, menos não ser embrulhado pelos arranjos de quase todos os proprietários de animais ... Sabe tudo mas perde sempre. Só a panelinha dos proprietários é que não se queixa. Ganha pela certa, ainda mesmo quando perdem os cavalos que cada um possui. $\mathrm{O}$ Povinho também ganha... experiência. E já não é pouco".

Como se pode perceber, a questão das falcatruas era algo que acontecia nos hipódromos em geral, tornando-se mesmo um grande problema nas décadas finais do século XIX (Melo, 2001). Por que então o Prado Guarani ficou conhecido como Maxixe, e não os outros?

O que percebemos é certa tensão entre diferentes grupos sociais que lideravam as agremiações. Os dirigentes do Prado Guarany até perspectivaram funcionar como os mais glamorosos hipódromos, tendo como modelo especialmente o Jockey Club. Todavia, frente a uma série progressivamente explícita de restrições, encontrou saídas peculiares, estratégias que acabaram garantindo alguma popularidade, o que incomodava ainda mais os outros clubes, imbuídos de controlar os sentidos e significados do turfe, bem como 
de garantir a menor divisão dos lucros, processo que Santos (2015) tratou como tentativa de monopolização.

Assim, mesmo que no seu tempo houvesse posições divergentes sobre o Prado Guarany, o que preponderou foi a fama de Maxixe, não os elogios que também se fizeram a seu funcionamento. A visão dos memorialistas é de que foi um completo fracasso, o que não corresponde àquilo que conseguimos investigar.

Há que se ter em conta também que houve um forte apagamento da memória da região na qual se encontrava o Prado Guarany. A área passou por muitas mudanças físicas - dificilmente aquela zona com ares de degradação lembraria a bela praia que existia antes - e de ocupação socioeconômica. De zona aristocrática, localizada nas redondezas do Palácio Imperial, tornou-se uma de ocupação industrial e operária. Não dificilmente a representação posterior do hipódromo tinha também em conta esse novo perfil.

Assim sendo, a experiência do Prado Guarany parece-nos um bom caso para discutir a relação do esporte com processos de urbanização, as tensões entre grupos sociais na dinâmica citadina, a articulação desses fatores com a construção de memórias - lembranças ou apagamentos - da cidade.

\section{REFERÊNCIAS}

ABREU, Martha. Festas religiosas no Rio de Janeiro: perspectivas de controle e tolerância no século XIX. Estudos Históricos, Rio de Janeiro, v.7, n.14, p.183-203, 1994. AZEVEDO, Arthur; SAMPAIO, Moreira. Cocota: revista comica de 1885 em 3 actos e 14 quadros. Música de Carlos Cavalier. Rio de Janeiro: Tip. Mont'Alverne, 1885.

CALDEIRA, Jorge. O processo econômico. In: SILVA, Alberto da Costa (Coord.) História do Brasil Nação (1808-2010). v.1 - Crise colonial e independência (18081830). Rio de Janeiro: Objetiva, 2011. p.161-204.

CARDOSO, Elizabeth D. et al. Zona Portuária: Saúde, Gamboa e Santo Cristo. Rio de Janeiro: Index, 1987.

COSTA, Cássio. O turfe de outrora. Rio de Janeiro: Vida Turfista, 1961.

EDMUNDO, Luiz. O Rio de Janeiro do meu tempo. Rio de Janeiro: Conquista, 1957.

FERREIRA, Lusirene C. F. Os clarões da liberdade: os impactos das notícias da abolição do Ceará no Rio de Janeiro. In: ENCONTRO "ESCRAVIDÃO E LIBERDADE NO BRASIL MERIDIONAL”, 6., 2013, Florianópolis. Anais... Florianópolis: Ed. UFSC, 2013.

FONSECA, Vitor Manoel M. da. No gozo dos direitos civis: associativismo no Rio de Janeiro, 1903-1916. Niterói: Muiraquitã, 2008. 
LABRONICI, Rômulo Bulgarelli. Na pata do cavalo: um estudo etnográfico com apostadores do turfe em agências credenciadas do Jockey Club Brasileiro. Tese (Doutorado em Antropologia) - Universidade Federal Fluminense (UFF). Niterói, 2016. MELO, Victor Andrade de. Cidade sportiva: primórdios do esporte no Rio de Janeiro. Rio de Janeiro: Relume Dumará; Faperj, 2001.

. Uma diversão civilizada: a patinação no Rio de Janeiro do século XIX (18721892). Locus, Juiz de Fora, v.23, n.1, p.81-100, 2017.

. Experiências de ensino da dança em cenários não escolares no Rio de Janeiro do século XIX (décadas de 1820-1850). Movimento, Porto Alegre, v.22, n.2, p.497$508,2016$.

MELO, Victor Andrade de; PERES, Fabio de Faria. A gymnastica no tempo do Império. Rio de Janeiro: 7 Letras, 2014.

MELO, Victor Andrade de; PERES, Fabio de Faria. Primórdios do esporte no Brasil: Rio de Janeiro. Manaus: Reggo, 2016.

PAULA, João Antônio de. O processo econômico. In: CARVALHO, José Murilo (Coord.) História do Brasil Nação (1808-2010). v.2 - A construção nacional (18301889). Rio de Janeiro: Objetiva, 2012. p.179-224.

PINTO, Ana Flávia Magalhães. Fortes laços em linhas rotas: literatos negros, racismo e cidadania na segunda metade do século XIX. Tese (Doutorado em História) IFCH, Universidade Estadual de Campinas (Unicamp). Campinas, 2014.

POPINIGIS, Fabiane. Proletários de casaca. Campinas: Ed. Unicamp, 2007.

PREFEITURA DA CIDADE DO RIO DE JANEIRO. Secretaria Especial de Comunicação Social. Imprensa revolucionária: o jornal como agente politizador. Rio de Janeiro, 2008.

SANTOS, João Manuel C. M. Economia do entretenimento: o processo de monopolização do primeiro empreendimento esportivo no Brasil (1850-1930). Economia e Desenvolvimento, Santa Maria, v.27, n.1, p.202-222, jan./jul. 2015.

TINHORÃO, José Ramos. História social da música popular brasileira. São Paulo: Ed. 34, 1998.

VAMPLEW, Wray. The turf: A Social and Economic History of Horse Racing. London: Allen Lane, 1976.

\section{NOTAS}

${ }^{1}$ Conflitos desencadeados por trapaças ou erros nos julgamentos dos resultados das provas.

${ }^{2}$ Chamava-se de Maxixe a tudo o que era considerado, na visão de alguns, de baixa qualidade e desprezível. A gíria acabou sendo utilizada para denominar uma dança considerada 
lasciva que se estruturou no final do século XIX. Para mais informações, ver TINHORÃO (1998).

${ }^{3}$ No cenário internacional, o turfe tem chamado a atenção de importantes historiadores. Entre tantos, merece destaque o celebrado estudo de Wray Vamplew (VAMPLEW, 1976). Para que se tenha ideia, a consulta ao International Journal of History of Sport aponta que 569 artigos foram publicados sobre o tema. No Brasil, Victor Andrade de Melo é o autor que mais tem se debruçado sobre $o$ assunto.

${ }^{4}$ Para um debate sobre a formação societária fluminense na segunda metade do século XIX, ver POPINIGIS (2007). Ver também CALDEIRA (2011) e PAULA (2012).

${ }^{5}$ Para mais informações, ver ABREU (1994) e MELO (2016).

${ }^{6}$ O guarda-livros jurisperito Saul Severino da Silva era personagem bem conhecido no Rio de Janeiro do século XIX. Dispondo de algum capital, tentava encontrar bons negócios em vários ramos.

${ }^{7}$ BRASIL. Decreto n. 7800, de 26 de agosto de 1880. Concede autorização a Saul Severino da Silva para organizar uma companhia denominada "Boat Rink".

${ }^{8}$ Segundo a Revista da Sociedade de Geografia do Rio De Janeiro (1888, p.244), as possibilidades de mobilidade pública ampliaram-se em várias regiões da cidade. A rede da Carris Urbanos tinha 61.915 m; a da São Cristóvão, 56.278 m; a da Jardim Botânico, 37.567 m; a da Vila Isabel, $36.000 \mathrm{~m}$, e a da Guarany, $8.000 \mathrm{~m}$.

${ }^{9}$ A cidade como um todo crescera rapidamente, dobrando o número de habitantes entre 1872 e 1890. Para mais informações, ver: https://censo2010.ibge.gov.br/sinopse/index. php?dados=6\&uf=00; acesso em: 23 fev. 2018.

${ }^{10}$ Para um debate sobre o valor dos ingressos, ver MELO; PERES (2014).

${ }^{11} \mathrm{O}$ periódico se notabilizou por seu caráter abolicionista, bem como por lançar olhares críticos às condições a que estavam submetidos os grupos minoritários da cidade (PINTO, 2014).

${ }^{12}$ Embora tenha logrado certa notoriedade na época, por problemas financeiros esse periódico de Manuel Carneiro acabou se unindo ao Brazil, dando origem ao Diário de Notícias. Vale ter em conta que o proprietário atuou e manteve relações com os jornais de José do Patrocínio (Gazeta da Tarde, Cidade do Rio).

${ }^{13}$ Esse periódico defendia os interesses dos proprietários de terras e de escravos (FERREIRA, 2013).

${ }^{14} \mathrm{Na}$ mesma data, o Derby Fluminense, de Vila Isabel, angariou 51:270\$000 (O Paiz, 22 dez. 1884, p.1).

${ }^{15}$ Para mais informações, ver texto de Fabio Peres em https://historiadoesporte.wordpress. com/2014/08/; acesso em: 26 dez. 2017.

${ }^{16}$ Inferimos que se trate do mesmo cronista por ter publicado na mesma seção do jornal, bem como pelo uso de palavras e estilo de narrativa semelhantes. 
${ }^{17}$ Jornal de caráter sindical, destacava-se pelas posições panfletárias (PREFEITURA..., 2008).

${ }^{18}$ Esse tema foi tratado por MELO (2001). As agremiações pediam constantemente apoio governamental, mas reagiam a qualquer tentativa de normatização.

${ }^{19}$ Arquivo Geral da Cidade do Rio de Janeiro. Notação: 41.3.32. Descrição: Corridas de cavalos: Prado Fluminense. Licença para o prado Vila Isabel Sociedade Sport Fluminense. Datas-limites: 1878-1889.

${ }^{20}$ Uma contundente crítica pode se ver em O Sportman, 15 maio 1887, p.2.

Artigo recebido em 7 de janeiro de 2018.

Aprovado em 15 de março de 2018. 